\title{
Risk-based Attestation of Fire Safety of Wooden Façades in Concrete-framed Residential Multistory Buildings
}

\author{
JUKKA HIETANIEMI, and TIMO KORHONEN \\ VTT Building and Transport \\ P.O. Box 1803 \\ FIN-02044
}

\begin{abstract}
This study presents a fire risk analysis on the impact on fire safety of installation of a wooden façade to a suburb residential multistory building belonging to the fire class P1 defined in the National Building Code of Finland, which in practice means a concreteframed building. The risk analysis and the associated fire simulations are made using state-of-the-art techniques in the fire safety sciences and technology. The results of the study reveal that with respect to the overall fire safety of the concrete-framed residential multistory buildings, the role of the combustible wood as the façade material is insignificant: as is inevitable, the calculations bring out a small increment in the probabilities of fire spread from the room-of-fire-origin to the apartments above, but this increment is small as compared to the influence of several other factors which are not regulated by the Fire Regulations. In particular, the relatively small amount of wood on the façade that is likely to contribute to the external flaming would cause a much higher risk if it was installed as a lining inside the apartment-of-fire-origin. It is shown that the results obtained for the selected example building can be generalized to other buildings with reasonably similar characteristics.
\end{abstract}

KEYWORDS: fire risk analysis, wooden façade, fire spread, external flaming, residential buildings, time-dependent event tree, probabilistic fire simulation

\section{INTRODUCTION}

The regulations and guidelines of the National Building Code of Finland (NBCF) specify limitations to the use of wood in the façades of residential multistory buildings, but they do not, however, prevent the use of wood. The issue is the way how the essential requirement of safety in case of fire is shown to be satisfied. To do this, there are two alternative ways: the other, more common way, is to design and execute the building by applying the prescriptions of the regulations and guidelines. The other way is to design and execute the building on the basis of design fire scenarios, which shall cover conditions likely to occur in the building (the performance-based fire design). In the latter case, one can employ solutions that differ from the fire classes and numerical criteria given in the regulations and guidelines of the Fire Regulations provided that they are proven to be safe. A prerequisite for the use of the alternative fire safety design approach is that there is solid, validated material to base the design on. The objective of the work described in this paper is to produce such material concerning use of wooden façades in concrete-framed residential multistory buildings (the P1 fire class in Finland).

We present results of a fire risk assessment concerning use of wooden façades in renovation. Focus of the analysis is in risks to life. The risk analysis approach used takes into account the influence of fire brigade extinguishing actions through application of the 
Time-Dependent Event Tree method developed by VTT [1,2]. The simulations on the fire development are carried out using the Probabilistic Fire Simulator tool of VTT enabling to carry out Monte Carlo simulations with various fire models ranging from analytical models to CFD models [3,4,5,6,7]. Calculating the Spearman's rank-order correlation coefficients gives quantitative measures on the sensitivity of the results on the model parameters. The methods are applied to analysis of fire risks of an existing residential building with 3-4 stories located in a suburb in the Eastern Helsinki. It is established that the influence of the wooden façade on the fire spread to the apartment above the apartment of fire origin is small as compared to other factors. For example, the distance of the fire brigade to the building has a stronger influence on the fire risks of than that of façade material. Also changes in the geometry of the building and the apartments affect the fire risks more than the choice of the façade material.

\section{DESCRIPTION OF THE BUILDINGS WITHIN THE SCOPE OF THE STUDY}

The buildings that we consider are residential multistory buildings built in the 1960's and 70 's, which are in need of renovation with the façades being an important target of renovation. Figure 1 shows a typical building of this type. The particular building shown is the example building of our analysis located in a suburb in the Eastern Helsinki, at a distance of $8 \mathrm{~km}$ from the nearest fire station. This particular building was selected as the subject of the study because there are plans to renovate its façades using wooden façades to replace the old concrete façades. There will be a ventilation slot with battens between the wooden cladding and the old façade. The building has 3-4 stories and there are neither windows in its gables nor combustible items such as waste containers in its vicinity.

a)

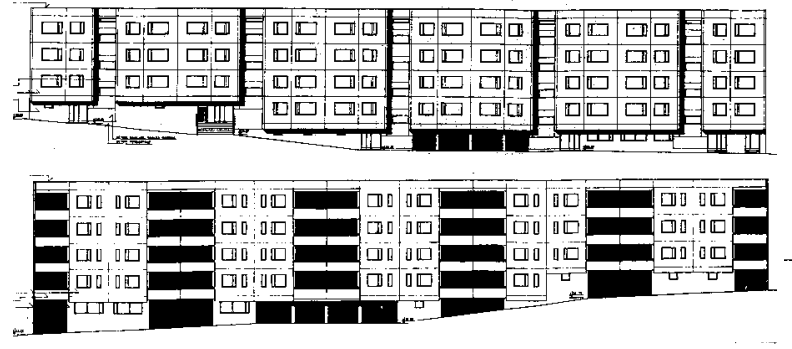

b)

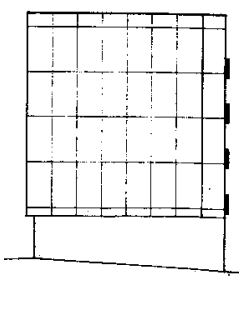

Fig. 1. a) Façades to the east and to the west and b) the gable of the example building.

\section{METHODS}

\section{Statistical Survey}

To establish the statistical basis to the work in this report, a survey was carried out on the material recorded in the Finnish National Accident Database (PRONTO) maintained by the Ministry of the Interior concerning residential fires and the role of the façade material in these fires. The years covered in the survey are 1996-2001 and the total number of fires in the statistical material is 2856 .

According to the analysis of the statistics reveals that in buildings with façade classified as a reaction-to-fire Euroclass B material (e.g., coated non-combustible board products), the portion of external ignitions of all fires is smaller than in buildings with façade 
classified as a Euroclass D material. The portions are the following: class Euroclass B: ca. $10 \%$ and Euroclass D: $15-20 \%$.

The average number of fires with interior ignition per year is 425 . Only $3 \%$ of these fires were registered to have spread to several fire compartments at fire brigade arrival. $74 \%$ of the fires with interior ignition remained confined to the room-of-fire origin or a part of it. First-aid extinguishing was able to put out the fire in $14 \%$ of the fires and in $8 \%$ of the fires it limited to the fire spread. Only $2 \%$ of the fires was a mentioned to have broken the fire-room window hence creating external flaming outside the room-of-fire origin, and only in three such incidents, the external flaming was accompanied by spread of the fire to the apartment located above the room-of-fire origin via breaking the windows of the above apartment (these incidents constitute $c a$. one out of thousand fires with interior ignition).

The annual average number of fires with exterior ignition was $c a .50$ or $c a .10 \%$ of all ignitions. The majority, $80 \%$, took place in the balcony and 'other' external ignitions constitute a portion of $2 \%$ (e.g., ignition of waste containers or shelters in the vicinity of the building or ignition of façades due to reasons of electrical origin, etc.) It can be estimated that about $15 \%$ of the fires that initiate in the balcony and are not extinguished by the first-aid extinguishing attempts spread into the apartment. Consequently, ca. 10\% of all fires starting in the balcony spread inside the apartment.

Analysis of the statistics gives a specific ignition frequency of $6, \ldots, 8 \times 10^{-6} \mathrm{fires} /\left(\mathrm{m}^{2} \cdot\right.$ year $)$ for the residential multi-store buildings considered in this study.

\section{Fire Scenarios}

The worst fire scenario concerning safety of life in the buildings considered in this study are the fires igniting inside the apartments that expose to danger the people in the apartment-of-fire origin as well as other people who have apartments in the same staircase since their safety may be threatened by the smoke spreading to the stairway. In this fire scenario, the façade material has no influence on the safety of life neither inside the apartment-of-fire origin nor in the stairway.

As the material of the façade is not relevant in the worst fire scenario, we consider here only fire scenarios which in the light of the statistical survey are much less important than the worst-case scenario. These secondary fire scenarios are ones that involve ignition of the façade 1) by the flames of a room fire that has flashed over and broken the fire room windows hence generating external flaming, 2) by the flames of fires in the balconies as well as 3) through external ignition. As explained below, we can limit our analysis to the fire scenario 1.

\section{Fires Starting Inside the Building}

The development of an apartment fire does not depend on the characteristics of the façade before the flames reach the façade, which usually takes places when a window of the apartment-of-fire origin breaks. The material of the façade has also no influence on the perception of the fire before the breakage and fallout of the windows of the apartment-offire origin. When the windows of the apartment-of-fire origin have been broken to form a ventilation opening, the flames and smoke burst out of this opening and expose the façade to heat; it is after this moment that the fire may be observed by passers-by. 
The fire scenario considered is modeled in three phases. First, we model the fire growth within the apartment-of-fire origin and the time of window breakage and fallout using a two-zone fire model augmented by a quantified expert-assessment of the window performance under enclosure fire heat exposure. Secondly, the size and temperature the external flames as well as the heat exposure from the flames to the façade of are evaluated using well-known empirical models. The contribution to the fire of the combustible façade material is incorporated into the modeling in this second phase. The third phase of the fire scenario description is the potential spread of the fire to other apartments via external flaming.

\section{External Ignitions}

According to the statistical survey covering the years 1996-2001, external ignitions make up $10 \%$ of ignitions in buildings belonging to the fire class P1. Most of these ignitions, $80 \%$, take place in the balcony. The most important hazard related to fires initiated in a balcony is the fire spread directly into the apartment via a window breakage, which is the case in about every tenth balcony fire. The statistics survey reveals that some fires started in a balcony have spread upwards (or horizontally). However, the National Building Code of Finland allows use of wood in the balcony walls and thus, we do not elaborate the risks related to wooden surfaces in balconies any further.

There are about ten incidents per year in which external ignition occurs elsewhere than in balcony, e.g., arson fires of waste containers or shelters in the vicinity of a building. In the example building, there are no combustibles in the vicinity and hence, this fire scenario is very unlikely. If, however, the unlikely external ignition occurs, it may cause upward fire spread along the façade, but hazards to life in such a fire scenario are low, because if the wooden façade is properly equipped with fire stops, the fire spread along the wooden façade is relatively slow and easily quenched by the firemen. Also the heat flux to windows from the flames of the burning wooden façade is relative low [10], most likely too low to induce breakage of the outer and the inner window pane [11]. If the flame front reaches the eaves, the fire may spread to the attic or a roof void space, but even in this case, the fire would not endanger the occupants because these is a fireresistant reinforced concrete slab separating this space from the apartments. Thus, we do not elaborate this fire scenario further.

\section{Modeling of the Spreading of a Flash-over Room Fire}

Modeling of the spread of the flash-over fire in an apartment includes three phases: 1) modeling of the fire in the room-of-fire-origin; 2) modeling of the external flaming and 3) assessing the probability of the spread of the fire to apartments above the room-of-fireorigin on the basis of the magnitude of the heat exposure caused by the external flaming. All these phases are subject of considerable uncertainties, which are included in the modeling so that the calculations are carrier out using the Monte Carlo technique with the Probabilistic Fire Simulator (PFS) program developed at VTT [3,4,5,6,7].

The development of the fire in the apartment-of-fire-origin is modeled using the CFAST [8] two-zone model program with fires in the different rooms as subscenarios. The door of the fire room is assumed to be open because if it is closed, the fire will most probably self-extinguish due to lack of oxygen. Our design fires include only those fires that become hot enough to be able to break the fire room window and hence expose the façade to heat. The proportion of these fires is estimated from the statistical data. The 
CFAST simulations are used to obtain the hot gas layer thickness and temperature $T_{g}$ which determine the breakage and fallout of the window. As all the rooms in the example building are roughly of the same size, there are no big differences in the times of the window breakage and fallout between the different subscenarios. Factors that do have a pronounced influence on the window fire performance, e.g., its installation to the frame, potential pre-stress fields, fissures in the window edges and the growth rate of the fire, are all subject of considerable uncertainties. These uncertainties are taken into account in the assessment of the breakage and fallout of the windows of the room-of-fire-origin as follows: the inner window pane is assumed to fallout when $T_{g}$ reaches $500{ }^{\circ} \mathrm{C}$ and the outer pane on the average $t_{\text {outer }}$ minutes later. Due to the uncertainties involved were treat the time lag $t_{\text {outer }}$ as a random quantity characterized by a lognormal distribution with the mode equal to 3 minutes and $80 \%$ fractile equal to 5 minutes.

When the window has broken to form an opening the flames expose the façade to heat. The size of the external flames is calculated using the Law model for external flaming $[11,12]$. In a ventilation limited case, the heat release rate (HRR) $\dot{Q}(\mathrm{~kW})$ of the room fire in the Law model depends on the dimensions of the opening and the room as follows:

$\dot{Q}=3150\left(1-e^{-0,036} / \%\right) A_{v} \sqrt{h_{e q}(W / D)}$

where $h_{e q}$ is the opening height (m), $A_{v}$ the area of the opening $\left(\mathrm{m}^{2}\right), W$ is the room width (m), $D$ is the room depth (m) and $O$ is the opening factor given by $O=A_{v} \sqrt{h_{e q}} / A_{t}$, where $A_{t}$ is the total area $\left(\mathrm{m}^{2}\right)$ of inner surfaces of the room. In a fuel-limited case, we calculate the maximum HRR on basis of the heat release per floor area, for which we use the value of $250 \mathrm{~kW} / \mathrm{m}^{2}$ recommended in the Eurocode 1 [12]. The height of the flame measured from the top of the opening, $L_{L}(\mathrm{~m})$, depends on the HRR and the opening dimensions according to the following formula [11]:

$L_{L}=h_{e q}\left(0,0237\left(\frac{\dot{Q}}{A_{v} \rho_{g} \sqrt{h_{e q} g}}\right)^{2 / 3}-1\right)$

where $\rho_{g}$ is the density of the hot gases $\left(\mathrm{kg} / \mathrm{m}^{3}\right)$ and $g$ is the acceleration of gravity $\left(\mathrm{m} / \mathrm{s}^{2}\right)$. The flame height given by the above expression equals to the height at which the flame temperature is equal to $540{ }^{\circ} \mathrm{C}$.

We take into account the variability of the various factors such as amount, properties and positioning of fuel in the fire room as well as the model uncertainty by allowing the HRR to vary within limits of $-20 \%-+50 \%$ (uniform distribution) in the Monte Carlo runs. This range of variability reflects the results of Harmathy [13], who compiled data from fully-developed room fires and studied their variability.

In case of a combustible façade, the contribution of the façade material to the fire increases the HRR. The increase of the HRR is calculated on the basis of the burning area and the HRR per unit area $\dot{q}_{\text {wood }}^{\prime \prime}$ of the façade material. We take into account the uncertainties involved in the burning of the façade by allowing the value of $\dot{q}_{\text {wood }}^{\prime \prime}$ to vary 
randomly according to a triangular distribution with lower and upper limits and the mode equaling $60 \mathrm{~kW} / \mathrm{m}^{2}, 120 \mathrm{~kW} / \mathrm{m}^{2}$ and $90 \mathrm{~kW} / \mathrm{m}^{2}$, respectively.

The region of applicability of the Law model ranges only up to the height at which the flame temperature equals $540{ }^{\circ} \mathrm{C}$. We, however, need information of the heat fluxes above this height and the model that we use for this region is the model for heat flux to a vertical wall from a flame adjacent to the wall by Back et al. [14]. This model uses the Heskestad plume model for the flame height $L_{f}(\mathrm{~m})$ given by

$L_{f}=0.23 \cdot \dot{Q}^{2 / 5}-1.02 D$

where $D$ is the diameter of the fire $(\mathrm{m})$. The dependence of the maximum heat flux $q_{\text {peak }}^{\prime \prime}\left(\mathrm{kW} / \mathrm{m}^{2}\right)$ on the HRR and the dependence of the heat flux on the height $z(\mathrm{~m})$ measured from the flame base are calculated using Eq. 4:

$$
\left.q_{\text {peak }}^{\prime \prime}=200 \mid 1-\exp \left(-0,09 \cdot \dot{Q}^{1 / 3}\right)\right] \text { and } q_{c l}^{\prime \prime}=\left\{\begin{array}{c}
q_{\text {peak }}^{\prime \prime}, z \leq 0,4 L_{f} \\
q_{\text {peak }}^{\prime \prime}-\frac{5}{3}\left(z / L_{f}-2 / 5\right)\left(q_{\text {peak }}^{\prime \prime}-q_{L_{f}}^{\prime \prime}\right), 0,4 L_{f}<z \leq 1,0 L_{f} \\
q_{L_{f}}^{\prime \prime}\left(z / L_{f}\right)^{-5 / 3}, z>1,0 L_{f}
\end{array}\right.
$$

where $q_{L_{f}}^{\prime \prime}\left(\mathrm{kW} / \mathrm{m}^{2}\right)$ is the heat flux at the tip of the flame. The models of Law and Back et al. were matched together so that heat flux value at the tip of the flame given by the Law model equals the value given by the model of Back et al.

The likelihood of fire spread to the apartments above the apartment-of-fire-origin is evaluated by comparing the calculated heat flux values (Eq. 4) to the experimental data of Mowrer on the external heat flux required to cause window breakage [10]. The procedure is the following: a heat flux equal to $35 \mathrm{~kW} / \mathrm{m}^{2}$ is assumed to break the window relatively rapidly (in 3 minutes) and a heat flux below $10 \mathrm{~kW} / \mathrm{m}^{2}$ is taken too weak to break the window. Combining the value of $35 \mathrm{~kW} / \mathrm{m}^{2}$ with the exposure time of 3 minutes gives the heat energy $Q_{b}=6,3 \mathrm{MJ} / \mathrm{m}^{2}$ required for the window breakage. This energy limit can be used to calculate the time lag of a window breakage at lower heat exposures than $35 \mathrm{~kW} / \mathrm{m}^{2}$. The uncertainties involved in this window breakage process are characterized in the Monte Carlo simulations by drawing the values for $Q_{b}$ from a symmetrical triangular distribution with minimum and maximum value ranging $\pm 20 \%$ around the mean value of $6,3 \mathrm{MJ} / \mathrm{m}^{2}$.

\section{The Time-dependent-event Tree Analysis}

The models described above give the time development of the potential fire spread in the absence of any attempts to detect and extinguish the fire. In reality, such development is extremely rare because generally, the fire is perceived and the fire services are alarmed to extinguishing the fire, which must be taken into account to get a realistic picture of the fire development.

This can be done by using the Time-Dependent Event-Tree (TDET) method developed by VTT [1,2], which differs from the conventional event-tree modeling in the important point that the TDET method takes explicitly into account the time dependence of the 
incident, while conventional event-trees only reflect the temporal development via the inherent causality of their structure. Explicit inclusion of the time development is very important, because the branching probabilities of the event trees depend strongly on time, e.g., the fire brigade extinguishing probability is strongly dependent on the size of the fire at the moment when the extinguishing attempts are started. The time dependence is incorporated in the TDET model so that time period under study is divided in to short intervals, each of which is analyzed by a conventional event tree shown in Fig. 2a. The evolution of the incident from its start to the end is obtained by combining the sequential event trees, which constitutes a non-trivial problem of probability calculus that we have solved by treating the fire as a Markovian process [1].

a)

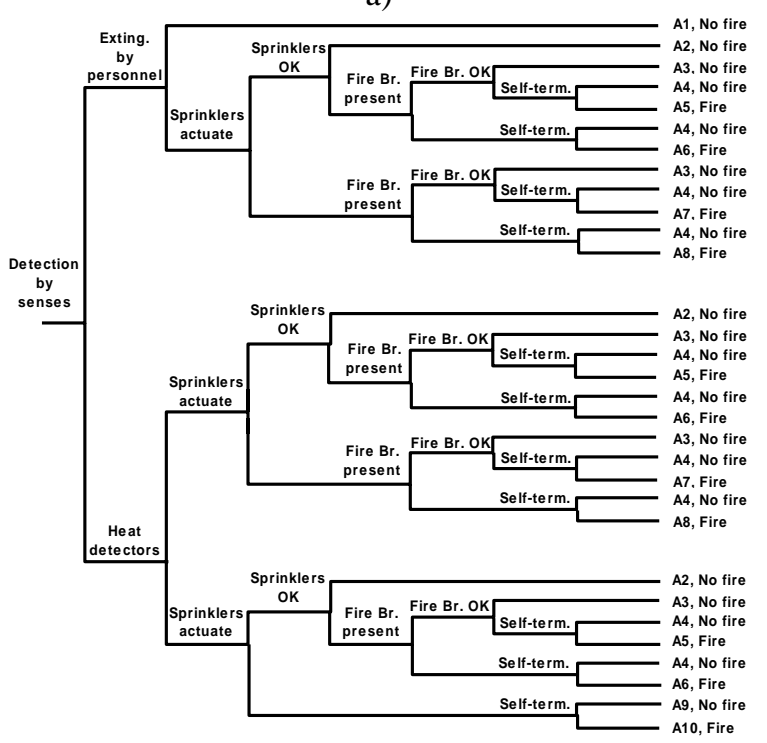

b)

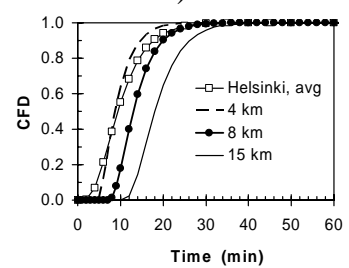

Fig. 2. a) The basic event tree of the TDET method. Not all branches are used in this application; the unused branches are cut-off by setting the branching probabilities

to zero. The event tree starts at fire detection, not at ignition, the frequency of which is a common factor scaling the results of the whole TDET analysis.

b) Cumulative frequency distributions of the operation times of rescue units in Helsinki.

Some of the branching probabilities are obtained from calculations and some are based on expert judgment. In this work we calculate the influence of the fire brigade operations on the basis of the data on the fire services response times [15] and the simulated fire development as well as the ending of the fire load, which can be calculated on the basis of the known fire load density data [12]. Expert judgment is applied to fire perception.

The fire brigade response time, i.e., the time delay from the alarm to the time when the fire brigade arrives at the fire scene consists of the turnout time (time from the alarm to the moment when the fire brigade leaves the fire station) and the travel time. Both these time factors are modeled on basis of their statistical distributions established by VTT [15], see Fig. 2b. For the time delay taken by the access and set up we use the data of Särdqvist [16]. The fire brigade is assumed to be able to control the fire so that the fire does not spread any further after the fire brigade starts its extinguishing operations, i.e., 
only those fire compartments that are involved in the fire at the fire brigade intervention are assumed to the affected by the fire.

The fire perception is divided to two categories based on the statistical findings:

1. Rapid perception: the occupant is awake and in good physical and mental state and is thus able to alarm the fire brigade as well as make an attempt of first-aid extinguishing. The time delay of perception is assumed to be about one or two minutes and that of the handling of the emergency call about one minute. In the incidents in this category, a portion $18 \%$ of the fires are put out by the first-aid extinguishing and also the fire brigade may be able to intervene the fire development inside the apartment and thus prevent external flaming. The percentage of this category is $70 \%$.

2. Slow perception: the apartment is either empty or the occupant is not able to act in the way as described in the category 1, in which case the fire will be noticed only after it breaks the windows. In this case, the fire brigade will not be able to influence to the fire development in the apartment and hence we assume that all these cases lead to our design fire, i.e., external flaming via the broken windows of the room-of-fire-origin. The percentage of this category is $30 \%$.

Some fires that have been perceived rapidly break the fire room windows and expose the façade before the fire brigade arrives at the scene. This means that our design fires are considerably more severe than real fires which include also small fires. This circumstance is in fact the design-fire-normalization problem that is well-known among fire-safety engineers using probabilistic approaches in their work. As we have the relevant statistical data available, we can use these data and normalize the frequency of the ignitions so that the results of our model agree with the statistical findings. The result of the normalization is that we must first assign a portion of $5 \%$ to internally ignited fires that become into contact with the façade and secondly that the probabilities obtained from the TDET analysis must be scaled down by a factor of ten.

The primary output of the TDET method is the probability that the fire has ended. The models described in the previous sections provide the other component of the risk, i.e., the potential magnitude of the damages at given times during the fire. Combination of the probabilities and the magnitudes of the consequences gives the risks.

\section{RESULTS FOR THE EXAMPLE BUILDING}

Figure 3 shows the probabilities per one fire for the fire spread from an apartment to the above apartments. The probabilities of fire spread one story or two stories upwards are shown, but not three stories up, because in that case, the probabilities are practically zero. 


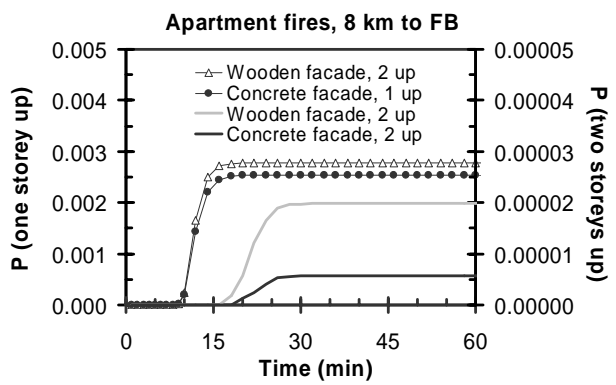

Fig. 3. Fire spread probabilities per one fire for the example building.

The probability of fire spread one storey up is about $0,25 \%$ per fire. It is almost the same for the concrete façade and the wooden façade, the probability for the wooden façade being only $9 \%$ higher $(0,27 \%$ per fire for the wooden façade vs. the $0,25 \%$ per fire for the concrete façade). Expressed as a frequency, the increment in the fire spread probability related to the wooden façade corresponds to one more incident in ten years in all residential multistory buildings in Finland. This means that if the material of all façades of residential multistory buildings in Finland was changed to wood, the difference caused by this chance in the frequency of fires that have spread to other compartments could not be discerned from the fire statistics, because the change would vanish in to the inherent statistical fluctuations.

Regarding the probabilities of fire spread two stories upwards, the probability for the wooden façade exceeds clearly that of the concrete façade. This difference is, however, totally irrelevant, because the absolute values of the probabilities are so low. The order of magnitude of the probability is only $0,001-0,003 \%$ per fire, which is in practice equal to zero, i.e., according to the results the spread of fire two stories upwards is a pure matter of chance.

\section{GENERALIZATION OF THE RESULTS}

The example building is a typical target building of the application of the results of this study. Although quite homogeneous in their architectural design, the residential suburb multistory buildings built in the 1960's and 1970's are not, however, identical, but have differences in the room and window lay outs and sizes as well as furnishings and other features dependent of the occupants. In this Chapter we analyze how the most typical changes in the building details, such as sizes and shapes of room and windows, affect the results we obtained for the example building.

The influence of the variations in the room and window sizes and shapes is studied by considering the following four cases: case $\mathrm{A}$ is the example building and the other cases are different variants of room and windows sizes with a non-combustible façade:

A. The case example building with a non-combustible façade.

B. Square-shaped rooms with areas equal to the room areas of the example building. Windows are similar to the windows in the example building. Noncombustible façade.

C. The plans of the rooms are similar to the example building. Windows are wide, extending the whole width of the rooms. Non-combustible façade. 
D. The dimensions of the room have been swapped so that the width equals to depth of rooms of the example building et vice versa and the window width is doubled as compared to the example building. Non-combustible façade.

Note that as all these variants have a non-combustible façade they satisfy the regulations and guidelines of the National Building Code of Finland.
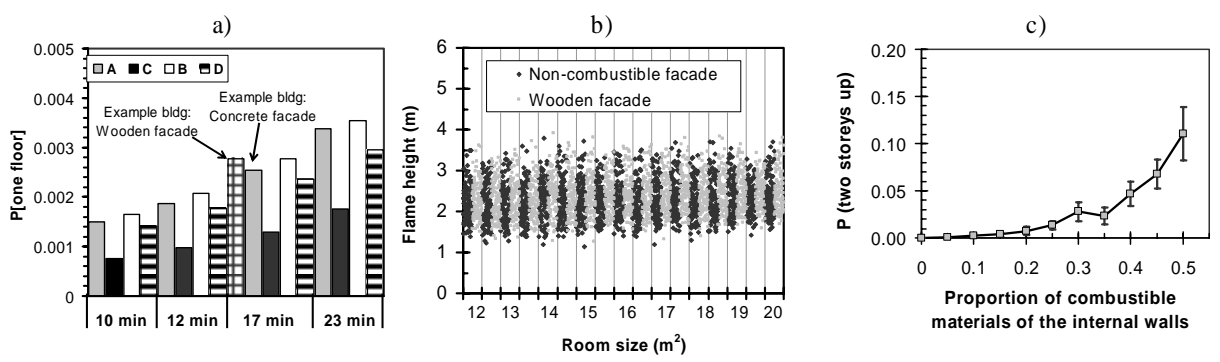

Fig. 4. a) Fire spread probabilities per one fire for the cases A, B, C and D. b) The influence of building characteristics exemplified by the room size (wood: the dark-grey markers, concrete: the light-grey markers). c) The dependence of fire-spread probability two stories upwards on the amount of wood installed as wall linings inside the apartments.

Figure 4a shows the probabilities of spread of a fire in an apartment to apartments above for these four cases. It is seen that the influence of the wooden façade to fire spread upwards is smaller that the influence of changes in the room or window sizes. Figure $4 \mathrm{~b}$ shows the influence of the general building characteristics with the effect of the room size depicted as an example. It is seen that 1) the most important factor with respect to the fire-spread probability, the external flame height, does not depend notably on the room size and 2) the results for the concrete façade and the wooden façade are practically the same (the scatter is due to variability of other factors in the Monte Carlo simulations). The independence of the results on the building characteristics apply to all other factors than the window width, which has some effect on the external flame height; however, the conclusion of the smallness of the effect of the wooden façade holds true also in this case. Figure 4c demonstrates how much stronger influence wood has on the fire spread when it is placed inside the fire room than on the façade (fire spread per one fire to an apartment two stories above the room-of-fire-origin). When the wooden surface is on façade, this probability is effectively zero but increases very strongly as the percentage of the wood placed as internal linings grows.

The results given above show that the influence of a wooden façade on the probability of fire spread in a concrete-framed residential multistory building is marginal and hence, does not give a significant increase in the fire risks of the building. In addition, the results show that the conclusions presented for the selected example building are not sensitive to changes in the general features of the building or other factors considered, including the fire brigade intervention as long as one is considering a building in a city or in a suburb of a city where the basic assumptions made regarding the fire operation times hold true. Thus, the results and conclusions have general validity beyond application to the selected example building.

It is noteworthy that the distance of the building to the fire station, the size and shape of windows as well as the furnishings and linings inside the apartments are more important 
factors than a wooden façade concerning the potential of fire spread to other apartments. Actually, the contribution to fire of a moderate-sized area of wood on the façade is so small that it is overwhelmed by the influence to the external flaming of any of the factors mentioned above. Especially, if the linings are partially or completely made of materials with the reaction-to-fire class of D-s2,d2 (e.g., wood paneling and boards) - which is allowed according to the Finnish Fire Regulations - the probability of fire spread to above apartments increases drastically as compared to the case when the wood surface forms only the cladding of the external wall.

\section{SUMMARY AND CONCLUSIONS}

The thorough fire risk analysis of the selected example building shows that the influence of installing a wooden façade on the fire spread in a concrete-framed residential multistory building is marginal and it does not give any significant increase in the fire risks of the building. A relative increment of about $10 \%$ per a fire in the probability of fire spread to an apartment above the room of fire-origin can be discerned by comparing the results for the example building with and without a wooden façade. In terms of absolute numbers, this relative change is completely insignificant as it means that even if every residential multistory building in Finland would be retrofitted by a wooden façade, there would be only one additional fire spread incident in ten years, which could not by any means be distinguished from the inherent statistical fluctuations. Another way to assess the fire-safety impact of installing of the wooden façade is to compare its influence to other factors: our results show that the influence of the wooden façade is smaller than the influence of several other, non-regulated factors, such as the room and window sizes and shapes as well the distance to the fire station and installing the wood as linings inside the apartments. The results obtained for the example building can be generalized to other buildings with reasonably similar characteristics.

\section{REFERENCES}

[1] Korhonen, T., Hietaniemi, J., Baroudi, D., and Kokkala, M., "Time-dependent Event-tree Method for Fire Risk Analysis: Tentative Results," Fire Safety Science - Proceedings of the Seventh International Symposium, International Association for Fire Safety Science, 2003, pp. 321-332.

[2] Hietaniemi, J., Korhonen, T., Joyeux, D., and Ayme, N., "Risk-based Fire Safety Engineering Approach to Obtain Balanced Structural Fire Resistance Requirements," Fire and Explosion Hazards, Proceedings of the Fourth International Seminar, University of Ulster, 2003, pp. 505-514.

[3] Hostikka, S., Keski-Rahkonen, O., and Korhonen, T., "Probabilistic Fire Simulator. Theory and User's Manual for Version 1.2," VTT Building and Transport. VTT Publications 503, 2003, 72 p. + App. 1 p.

[4] Hostikka, S., and Keski-Rahkonen, O., "Probabilistic Simulation of Fire Scenarios,” Nuclear Engineering and Design, 224, pp. 301-311, (2003).

[5] Hietaniemi, J., Hostikka, S., and Korhonen, T., "Probabilistic Fire Simulation," Proc. of the 5th Int'l Conference on Performance-Based Codes and Fire Safety Design Methods, Society of Fire Protection Engineers, 2004, pp. 280-291. 
[6] Hostikka, S., Korhonen, T., amd Keski-Rahkonen, O., "Two-model Monte Carlo Simulation of Fire Scenarios," Fire Safety Science - Proceedings of the Eighth International Symposium, September 18-23, 2005, Beijing, China, 12 p.

[7] Hostikka, S.,and Keski-Rahkonen, O., "Advanced Probabilistic Simulation of NPP Fires,” Paper M628, Proceedings of SMiRT18, China, August 8-12, 2005.

[8] Peacock, R.D., Forney, G.P., Reneke, P., Portier, R., and Jones, W.W., “CFAST, The Consolidated Model of Fire Growth and Smoke Transport," Gaithersburg, National Institute of Standards and Technology, NIST Technical Note 1299, 1993, 118 p. + app. 116 p.

[9] Hakkarainen, T., and Oksanen, T., "Fire Safety Assessment of Wooden Facades," Fire and Materials, 26, pp. 7-27, 2002.

[10] Mowrer, F.W., "Window Breakage Induced by Exterior Fires," National Institute of Standards and Technology Report NIST-GCR-98-751, Gaithersburg, MD,1998, 40 p.

[11] Law, M., and O’Brien, T., "Fire Safety of Bare External Structural Steel," Constrado, 1981.

[12] CEN "Eurocode 1: Actions on Structures-Part 1-2: General Actions - Actions on Structures Exposed to Fire,” CEN, Brussels, 2002, 59 p. (EN 1991-1-2:2002 E.).

[13] Harmathy, T.Z. "Some Overlooked Aspects of the Severity of Compartment Fires,” Fire Safety Journa, 3, pp. 261-271, (1980/81).

[14] Back, G., Beyler, C.L., DiNenno, P., and Tatem, P., "Wall Incident Heat Flux Distributions Resulting from an Adjacent Fire,” Fire Safety Science Proceedings of the Fourth International Symposium, International Association for Fire Safety Science, 1994, pp. 241252.

[15] Tillander, K., and Keski-Rahkonen, O., "Influence of Fire Department Intervention to the Fire Safety of a Building Assessed Using Fire Risk Analysis," Proc. of the 3rd Int'l Conference on Performance-Based Codes and Fire Safety Design Methods, Society of Fire Protection Engineers, 2000, pp. 247-256.

[16] Särdqvist, S., "Real Fire Data. Fires in Non-Residential Premises in London 1994-1997,” Lund University Report 7003, 1998, 59 p. 